\title{
Management of ocular inflammation and pain following cataract surgery: focus on bromfenac ophthalmic solution
}

\author{
Hyung Cho' \\ Kenneth J Wolf' \\ Eric J Wolf ${ }^{2}$ \\ 'Department of Ophthalmology, \\ Albert Einstein College of Medicine, \\ Montefiore Medical Center, Bronx, \\ New York, USA; ${ }^{2}$ Department \\ of Ophthalmology, Edward S. \\ Harkness Eye Institute of Columbia \\ University College of Physicians \\ and Surgeons, New York, NY, USA
}

\begin{abstract}
Recently, several new ophthalmic NSAID products have been introduced for commercial use in the United States. The purpose of this review is to briefly overview the ophthalmic NSAIDs currently in use and to discuss the management of postoperative ocular inflammation and pain following cataract surgery with a particular focus on bromfenac ophthalmic solution $0.09 \%$. Bromfenac ophthalmic solution $0.09 \%$ is indicated for the reduction of ocular pain and inflammation following cataract surgery. Studies have shown that bromfenac ophthalmic solution $0.09 \%$ has equivalent efficacy to the other topical NSAIDs in reducing postsurgical inflammation and controlling pain. The unique chemical structure of bromfenac makes it both a potent inhibitor of the COX-2 enzyme and a highly lipophilic molecule that rapidly penetrates to produce early and sustained drug levels in all ocular tissues. Clinically, these pharmacokinetic features are manifested in a rapid reduction of postsurgical inflammation and pain with bid dosing. Bromfenac ophthalmic solution $0.09 \%$ is a versatile agent and is effective when used as either monotherapy or as an adjunct therapy to steroids.
\end{abstract}

Keywords: bromfenac, ophthalmic NSAIDs, ocular inflammation

\section{Overview of postoperative ocular inflammation}

In ocular tissue, arachidonic acid is metabolized by cyclooxygenase (COX) to prostaglandins which are the most important lipid-derived mediators of inflammation. ${ }^{1}$ Ocular inflammation is characterized by redness, swelling, and/or pain associated with irritation or trauma to the eye. Surgical trauma causes a trigger of the arachidonic acid cascade which in turn generates prostaglandins (PG) by activation of COX-1 and COX-2. Phospholipids in the cell membrane are the substrate for phospholipase A to generate arachidonic acid from which a family of chemically distinct prostaglandins and leukotrienes are produced. ${ }^{2}$ Clinical symptoms of prostaglandin production include hyperemia, miosis, impaired vision, pain, and diminished visual acuity secondary to cystoid macular edema (CME). ${ }^{3}$

Ocular actions of prostaglandins are manifested in three ways. ${ }^{4}$ Firstly, they act on intraocular pressure (IOP). Prostaglandin $\mathrm{E}_{1}\left(\mathrm{PGE}_{1}\right)$ and prostaglandin $\mathrm{E}_{2}\left(\mathrm{PGE}_{2}\right)$ increase the IOP by local vasodilation and increased permeability of the blood-aqueous barrier. Conversely, prostaglandin $\mathrm{F}_{2}-\alpha\left(\mathrm{PGF}_{2}-\alpha\right)$ lowers the IOP which is attributed to increased uveoscleral outflow. Secondly, they act on iris smooth muscle to cause miosis. Thirdly, prostaglandins cause vasodilation and increase the vascular permeability resulting in increased aqueous humor protein concentration. ${ }^{4}$

Prostaglandin synthesis can be reduced by inhibiting phospholipase $\mathrm{A}_{2}$, which inhibits the release of arachidonic acid from cell membrane phospholipids, or by inhibiting the conversion of arachidonic acid to prostaglandins via the COX pathway. Different classes of anti-inflammatory medications may block different portions of this pathway. 
Corticosteroids interfere with the activity of phospholipase $\mathrm{A}_{2}$, thereby inhibiting the release of arachidonic acid and the production of all arachidonic acid metabolites, including prostaglandins. ${ }^{5}$ In constrast, nonsteroidal anti-inflammatory drugs (NSAIDs) nonspecifically and irreversibly inhibit the synthesis of prostaglandins by interfering with the activity of COX-1 and COX-2 (Figure 1). ${ }^{5}$

There are 2 important isoforms of COX. COX-1 is an enzyme that is expressed constitutively in almost all tissues, particularly in the gastrointestinal tract, platelets, endothelial cells, and kidney. ${ }^{6} \mathrm{COX}-1$ is responsible for the production of prostaglandin $\mathrm{G} 2\left(\mathrm{PGG}_{2}\right)$, which is important for homeostatic functions, such as maintaining the integrity of the gastrointestinal mucosa, mediating platelet function, and regulating renal blood flow. ${ }^{7}$ The expression of COX- 2 occurs in response to the exposure to a noxious stimulus. It has been demonstrated in rats that $\mathrm{COX}-2$ is the primary mediator for ocular inflammation. ${ }^{8}$ Therefore, inhibition of COX-2 is thought to be the most important therapeutic mechanism of ophthalmic NSAIDs.

As described above, the two main treatments for ocular inflammation are topical corticosteroids or NSAIDs. The corticosteroids, which are considered the gold standard for the treatment of ocular inflammation, are associated with an increased incidence of adverse events that warrant their judicious use. ${ }^{3}$ These adverse events include cataract formation, a rise in IOP, increased susceptibility to microbial infections due to a suppressed host immune response and retardation in corneal epithelial and stromal wound healing. ${ }^{9}$ Steroids may not be safe for periods of extended use, as prolonged use is associated with the development of glaucoma, visual acuity defects and loss of visual field, and posterior subcapsular cataract formation. ${ }^{3}$ Cataract surgeons have therefore been interested in alternative treatments for postoperative pain and inflammation with effectiveness equivalent to steroids but with fewer complications.

\section{Classification of NSAIDs}

A safer alternative to corticosteroids for the treatment of ocular inflammation are the NSAIDs. NSAIDs comprise several chemically heterogeneous classes of drugs which possess potent COX inhibitory activity. Topical NSAIDs are classified into six groups based on their chemical composition: indoles, phenylacetic acids, phenylalkanoic acids, salicylates, fenamates, and pyrazolones. Salicylates, fenamates, and pyrazolones are considered too toxic to be used in the eye. ${ }^{10,11}$ Most of the NSAIDs are weakly acidic drugs, which ionize at the $\mathrm{pH}$ of the lacrimal fluid and therefore have limited permeability through the anionic cornea which has an isoelectric point $\mathrm{pI}$ of 3.2. ${ }^{12}$ Reducing the $\mathrm{pH}$ of the formulation increases the unionized fraction of the drug which enhances permeation. Being acidic, NSAIDs are inherently irritant, and reducing the $\mathrm{pH}$ of formulation further increases their irritation potential, and decreases their aqueous solubility. ${ }^{13}$ In addition, the anionic nature of NSAIDs lends to the formation of insoluble complexes

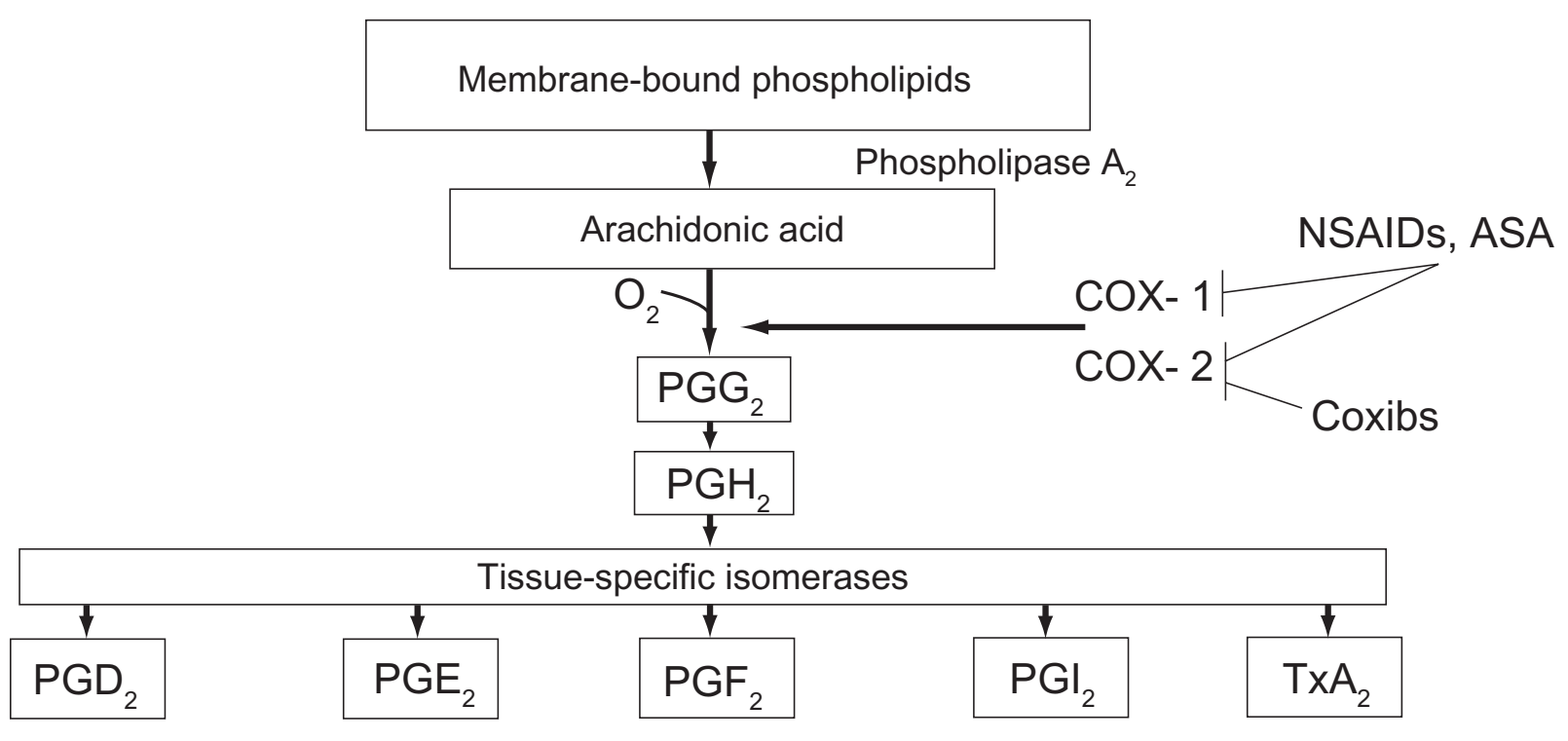

Figure I Prostaglandin and thromboxan biosynthesis. After FitzGerald and Patrono $2001 .{ }^{84}$

Abbreviations: COX, cyclooxygenase; coxibs, COX-2 inhibitors; PG, prostaglandin; TxA , thromboxane $A_{2}$; NSAID, nonsteroidal anti-inflammatory drug; ASA, aspirin. 
with cationic quaternary ammonium preservatives, such as benzalkonium chloride. ${ }^{14,15}$ Thus, it has proved difficult to formulate topical NSAID formulations that are comfortable when applied topically to the eye.

Four topical ocular NSAIDS are currently approved by the US Food and Drug Administration (FDA) for the treatment of postoperative inflammation after cataract surgery. They are diclofenac sodium ophthalmic solution $0.1 \%$ (Voltaren ${ }^{\circledR}$, Novartis), ${ }^{16}$ ketorolac tromethamine ophthalmic solution $0.5 \%$ (Acular ${ }^{\circledR}$, Allergan) ${ }^{17}$ nepafenac ophthalmic suspension $0.1 \%\left(\text { Nevanac }^{\circledR}, \text { Alcon }\right)^{18}$ and bromfenac ophthalmic solution $0.09 \%$ (Xibrom ${ }^{\circledR}$, Ista). ${ }^{19}$ The FDA approved dosing for diclofenac and keterolac is 4 times daily. Nepafenac is FDA approved for a thrice-daily dosing regimen beginning 1 day before cataract surgery. The FDA approved dosing for bromfenac is twice daily, with no predosing before surgery necessary (Table 1). ${ }^{16-19}$

Ophthalmic NSAIDs currently play 4 principal roles in ophthalmic surgery, including the prevention of intraoperative miosis during cataract surgery, management of postoperative inflammation, the reduction of pain and discomfort after cataract and refractive surgery, and the prevention and treatment of cystoid macular edema (CME) after cataract surgery. ${ }^{2,20,21}$

Studies comparing NSAIDs with corticosteroids have demonstrated no significant difference in the results between these treatments. ${ }^{11,22,23}$ However, NSAID treatment appears to be more effective than topical corticosteroids in re-establishing the blood-aqueous barrier. ${ }^{22,24}$ Many studies that analyzed the effects of NSAIDs on postoperative inflammation included the concurrent administration of corticosteroids, suggesting that NSAIDs and corticosteroids have the potential for synergistic activities. ${ }^{21,24,25}$ The beneficial effects of NSAIDs over corticosteroids include stabilization of IOP, provision of analgesia and reduction of the risk of secondary infections. ${ }^{26}$

\section{Introduction to bromfenac}

Bromfenac sodium ophthalmic solution $0.1 \%$ was first approved in May 2000 as Bronuck ${ }^{\circledR}$ (Senju Pharmaceutical
Company, Ltd., Osaka, Japan) and is presently approved by the Ministry of Health in Japan for the clinical indications of the treatment of postoperative inflammation, blepharitis, conjunctivitis, and scleritis. ${ }^{19}$ The same formulation was approved by the FDA in March 2005 as Xibrom ${ }^{\circledR}$ (bromfenac ophthalmic solution 0.09\%). Bromfenac ophthalmic solution $0.09 \%$ is indicated for the treatment of postoperative inflammation in patients who have undergone cataract extraction. The recommended dosage of bromfenac ophthalmic solution $0.09 \%$ is one drop in the affected eye(s) twice daily beginning 24 hours after cataract surgery and continuing through the first 2 weeks of the postoperative period. ${ }^{19}$

\section{Pharmacology of bromfenac Chemistry}

Bromfenac sodium is designated chemically as sodium 2-amino-3-(4-bromobenzoyl) phenylacetate sesquihydrate, with an empirical formula of $\mathrm{C}_{15} \mathrm{H}_{11} \mathrm{BrNNaO}_{3} \cdot 1 \frac{1}{2} \mathrm{H}_{2} 0$. The structural formula for bromfenac sodium is shown in Figure 2.

Nepafenac (Figure 3) unlike other topical NSAIDs, is not a free acid. Rather, it is an NSAID prodrug, a property that allows it to rapidly cross the cornea. In vitro, nepafenac permeates the human cornea 6 times faster than diclofenac. ${ }^{27}$ After penetrating the cornea, nepafenac undergoes rapid bioactivation to amfenac in ocular tissues (Figure 3). ${ }^{27}$ The structure of bromfenac is identical to amfenac, with the key exception of a bromine atom at the $\mathrm{C} 4$ position. ${ }^{28,29,30}$ The addition of the bromine imparts three important characteristics to the bromfenac molecule to distinguish it from other NSAIDs. First, bromine enhances the lipophilicity of the molecule and facilitates its penetration through the cell membrane of various tissues, including ocular tissues, which in turn gives increased duration of action and enhanced COX-2 inhibitory activity. ${ }^{29,30}$ The commercially available formulation is buffered to a $\mathrm{pH}$ of 8.3 and contains polysorbate 80 as solubilizer and benzalkonium chloride $(0.005 \%)$ as preservative. ${ }^{1}$ Second, bromination in the 4 position of the phenyl ring increases the duration of analgesic and antiinflammatory activity. ${ }^{28,30}$ Third, the bromine modification may result in an enhanced inhibitory effect on COX-2.

Table I Commercially available topical NSAIDs indicated for pain and inflammation associated with cataract surgery ${ }^{16-19}$

\begin{tabular}{lllll}
\hline Generic & Brand & Manufacturer & Chemical class & Formulation \\
\hline Ketorolac & Acular & Allergan & Phenylalkanoic acid & $0.5 \%$ solution \\
Diclofenac & Voltaren & Novartis & Phenylacetic acid & $0.1 \%$ solution \\
Nepafenac & Nevanac & Alcon & Arylacetic acid & $0.1 \%$ suspension \\
Bromfenac & Xibrom & Bausch and Lomb & Phenylacetic acid & $0.09 \%$ solution \\
\hline
\end{tabular}




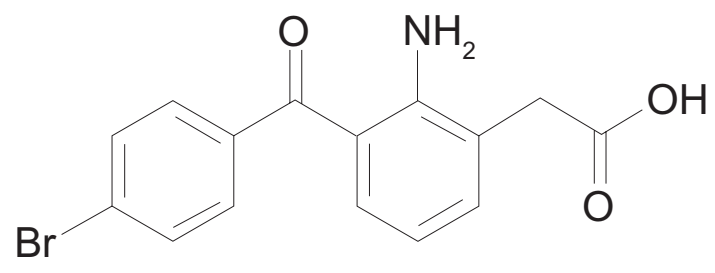

Figure 2 Chemical structure of bromfenac.

\section{Pharmacokinetics}

NSAIDs vary in their relative potency against COX-1 and COX-2. Although the exact plasma concentration of bromfenac following ocular administration is unknown, the relative potency is assessed by determining the concentration of drug required to inhibit the COX enzyme activity by $50 \%$ (inhibitory concentration $50 \%$ or $\mathrm{IC}_{50}$ ). A smaller $\mathrm{IC}_{50}$ value signifies greater inhibition of the enzyme. ${ }^{7}$ In vitro studies have shown that the inhibitory effects of bromfenac on COX-2 are 3.7 times greater than those of diclofenac, ${ }^{31} 6.5$ times greater than those of amfenac, ${ }^{32}$ and 18 times more potent than those of ketorolac (Tables 2 and 3 ). ${ }^{33}$ The COX-2 purified from rabbit alveolar macrophage was used for the COX-2 enzyme inhibition assay of bromfenac, diclofenac, and amfenac. ${ }^{31,33}$ In another study involving arachidonic acid and carrageenan-induced conjunctival edema in rabbits, bromfenac was found to be 3.8 and 10.9 times more potent than indomethacin and pranoprofen as an inhibitor of prostaglandin production. ${ }^{34}$ It is important to keep in mind, however, that studies examining relative inhibitory $\mathrm{COX}$ activity of NSAIDs often utilize differing protocols and enzyme sources. Therefore, the comparative assessment of NSAID $\mathrm{IC}_{50}$ is not directly correlated with clinical indicators of therapeutic effectiveness.

\section{Pharmacokinetic studies of bromfenac on animals}

Two animal studies have demonstrated that bromfenac ophthalmic solution rapidly achieves measurable levels in all major ocular tissues and that detectable levels are sustained

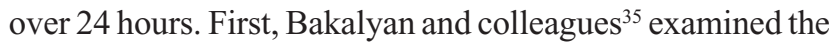
distribution of a single application of radiolabeled bromfenac ophthalmic solution in New Zealand White Rabbit eyes.
After the administration of $50 \mu \mathrm{L}$ of C-bromfenac sodium ophthalmic solution to the right eyes of 14 randomly assigned animals, samples of the cornea, aqueous humor, iris/ciliary body, choroid, and retina were collected at multiple time points for analysis. Peak concentrations of radiolabeled bromfenac were observed in the aqueous humor and most of the ocular tissues at 2 hours. Concentrations were highest in the cornea and bromfenac was detected in all samples over 24 hours. ${ }^{35}$ By comparison, in a separate but similar evaluation of C-nepafenac with 3 times the commercially available dose, initial penetration into ocular tissues produced detectable drug levels in the cornea and iris/ciliary body beyond 24 hours but not in the aqueous humor or choroid beyond 12 hours and in the retina beyond 6 hours. ${ }^{36}$

Second, McNamara and associates ${ }^{37}$ recently replicated Bakalyan's results with a single drop of bromfenac. In the same animal model, peak concentrations of C-bromfenac were observed at or before 2 hours with measurable levels in all ophthalmic tissues, including the retina, over 24 hours, after a single ophthalmic dose. Although the clinical significance of these animal studies is unknown, the data suggest that because bromfenac ophthalmic solution rapidly reaches sustained concentrations in all ocular tissues, it may find utility in treating disorders associated with inflammation in other ocular tissues. ${ }^{7}$

\section{Clinical studies of bromfenac ophthalmic solution}

Clinical studies to date have shown mixed results on which topical NSAIDs are the most effective.

\section{Pharmacokinetic studies of bromfenac on dosing}

Ogawa and colleagues ${ }^{34}$ evaluated the pharmacokinetic profile of bromfenac ophthalmic solution $0.09 \%$ in human subjects undergoing cataract surgery, in part to validate the sufficiency of bid dosing. A single drop of bromfenac ophthalmic solution at the commercial concentration was administered to 54 subjects at a variety of specified time points before cataract surgery. At the start of each case,<smiles>NC(=O)Cc1cccc(C(=O)c2ccccc2)c1N</smiles>

Figure 3 Deamination of nepafenac to the active compound amfenac. 
Table 2 Relative potency of bromfenac, diclofenac, and amfenac in vitro: $I_{50}$ values of cyclooxygenase- 2 (COX-2) $)^{7,31,33}$

\begin{tabular}{ll}
\hline & IC $_{50}$ COX-2 (nM) \\
\hline Bromfenac & 23 \\
Diclofenac & 85 \\
Amfenac & 150 \\
\hline
\end{tabular}

$100 \mu \mathrm{L}$ of aqueous humor was extracted for analysis. The results showed rapid absorption (within 15 minutes) with the peak aqueous humor concentration of bromfenac occurring at 150 and 180 minutes after instillation. ${ }^{34}$ This study showed effective concentrations in the aqueous humor persisting for 12 hours after a single application, which suggests that bid dosing is sufficient to maintain anti-inflammatory efficacy.

\section{Optimal concentration of bromfenac}

Masuda and colleagues performed a multicenter, phase 2 clinical study evaluating the optimal concentration of the ophthalmic solution of twice-daily $0.01 \%, 0.1 \%$, and $0.2 \%$ bromfenac drops in 228 cataract cases. The $0.1 \%$ and $0.2 \%$ groups showed superior anti-inflammatory activity, and although adverse events did not seem concentration dependent, the $0.1 \%$ concentration was deemed optimal to minimize any potential for corneal toxicity. ${ }^{38}$

\section{Pharmacodynamics of bromfenac vs nepafenac/amfenac vs ketorolac}

Walters et $\mathrm{al}^{39}$ researched the in vivo pharmacokinetics and in vitro pharmacodynamics of nepafenac, amfenac, ketorolac, and bromfenac in 5 private ophthalmology practices throughout the United States. Patients requiring cataract extraction were randomized to 1 of 3 treatment groups: nepafenac, ketorolac, or bromfenac. Patients were administered 1 drop of the test drug before cataract surgery and an aqueous humor sample was collected during paracentesis and later analyzed for drug concentration. In addition, COX-1 and COX-2 inhibitory activities were determined via the in vitro measurement of $\mathrm{PGE}_{2}$ inhibition. Seventy-five patients participated in this study and Walters et al determined that nepafenac showed significantly greater ocular bioavailability and greater potent

Table 3 Relative potency of bromfenac and ketorolac in vitro: $\mathrm{IC}_{50}$ values of cyclooxygenase-2 (COX-2)

IC50 COX-2 (nM)

Bromfenac 6.6

Ketorolac

120
COX-1 inhibition than any other drug tested and amfenac demonstrated greater potency and COX-2 inhibition than ketorolac or bromfenac. ${ }^{39}$

\section{$\mathrm{PGE}_{2}$ inhibition of bromfenac vs ketorolac} Bucci et $\mathrm{al}^{40}$ compared aqueous drug concentrations and $\mathrm{PGE}_{2}$ levels in patients treated with ketorolac $0.4 \%$ and bromfenac $0.09 \%$ at trough dosing and found that higher aqueous levels $(130.5+37.8 \mathrm{ng} / \mathrm{mL}$ and $6.2+3.1 \mathrm{ng} / \mathrm{mL})$ and greater $\mathrm{PGE}_{2}$ inhibition $(204.2 \mathrm{pg} / \mathrm{mL}+95.5$ [SD] vs $263.7+90.0)$ were observed in cataract surgery patients treated with ketorolac $0.4 \%$ than in patients treated with bromfenac $0.09 \%$ at trough dosing, suggesting that ketorolac $0.4 \%$ may provide better control of prostaglandin-mediated inflammation than bromfenac $0.09 \%$ administered twice a day.

\section{COX inhibition of bromfenac vs ketorolac}

Another study analyzing NSAID COX inhibitory activities compared the COX inhibitory activity and ocular antiinflammatory effects of ketorolac and bromfenac. ${ }^{32}$ The authors reported that ketorolac inhibited COX-1 more strongly than bromfenac while bromfenac had greater COX-2 inhibitory activity than ketorolac. A similar relationship was also found in the Walters study, ${ }^{39}$ which validates the results of Waterbury et al. ${ }^{32}$

\section{Bromfenac vs diclofenac ophthalmic solution}

Several subsequent clinical studies have compared the efficacy of bromfenac ophthalmic solution with diclofenac ophthalmic solution in reducing inflammation after cataract surgery. ${ }^{41-43}$

\section{Prospective, single-center randomized trial}

Kawaguchi and associates ${ }^{41}$ found that bromfenac has a more rapid onset of anti-inflammatory activity than diclofenac based upon a prospective, single-center, randomized trial in 38 subjects (49 eyes) who underwent cataract surgery. Measuring aqueous flare levels, the group noted that at each time point, flare was lower in the bromfenac group than in the diclofenac group, a difference that was statistically significant during the first 2 weeks of surgery $(p<0.05){ }^{41}$

\section{Retrospective/prospective analysis}

Takamatsu et $\mathrm{al}^{42}$ found that bromfenac ophthalmic solution exerted anti-inflammatory effects that were comparable to or greater than diclofenac ophthalmic solution, including comparable suppression of $\mathrm{CME}$ and posterior 
capsule opacification. Of clinical importance, bromfenac was associated with less corneal epitheliopathy than diclofenac. Subjects at 2 facilities were divided into bromfenac and diclofenac treatment groups after uncomplicated cataract surgery. A retrospective analysis of data from the first facility included a total of 228 eyes from 157 subjects, whereas a prospective analysis from the second facility included a total of 58 eyes from 30 subjects. Early differences in the flare level seen between the two treatment arms disappeared by the 28th postoperative day. However, the incidence of corneal epitheliopathy was significantly higher in the diclofenac group in the first center, despite tid dosing in both arms. ${ }^{42}$

\section{Multicenter, open-label clinical study}

Ohara and associates ${ }^{43}$ also compared the effects of bromfenac ophthalmic solution with diclofenac ophthalmic solution on postoperative inflammation after cataract phacoemulsifcaition and intraocular lens implantation. Their multicenter, open-label, clinical study divided 111 subjects into 2 treatment groups, each of which received 2 drops of bromfenac or diclofenac preoperatively, and then bromfenac bid or diclofenac tid with concomitant ophthalmic steroid and anti-infective for 4 weeks, beginning the day after surgery. Anterior chamber cells and flare and corneal epithelial disorder in the two groups showed no statistically significant difference after day $7 .{ }^{43}$

\section{Phase III trials}

Two phase 3 clinical trials were performed in the United States to evaluate the efficacy, safety, and tolerability of bromfenac ophthalmic solution $0.09 \%$ in treating postoperative inflammation and pain after cataract surgery. The study consisted of 2 randomized, double-masked, placebo-controlled United States trials in which subjects with a summed ocular inflammation score (SOIS = anterior chamber cell score plus flare score, each on a scale of 0-4) of $>3$ after cataract surgery were assigned to bromfenac or placebo in a 2:1 ratio following surgery. Subjects selfinstilled 1 drop of the assigned test agent twice daily for 14 days and were followed for an additional 14 days for safety evaluation. The primary endpoint was reduction of ocular inflammation assessed 14 days after surgery using a slit lamp binocular microscope. Subjects were excluded if they used any ocular, topical, or systemic medication that could interfere with normal lacrimation, wound healing, the test agent, or the interpretation of study results within 1 week of study visit $1 .^{44}$ This study had no pretreatment, no ophthalmic corticosteroid use, and included only subjects with moderate to severe ocular inflammation after cataract surgery.

In the intent-to-treat analyses of both studies, a significant effect of bromfenac on ocular inflammation after cataract surgery was demonstrated $(62 \%-66 \%$ vs $40 \%-48 \%$; $\mathrm{p}<0.0001)$. These results demonstrate that bromfenac ophthalmic solution $0.09 \%$ dosed twice a day for 14 days was effective for the reduction of ocular inflammation (to trace or cleared). Although the primary efficacy endpoint was a reduction of inflammation to trace or cleared cells and no flare, there was an additional assessment of marked improvement in inflammation. Findings of conjunctival erythema, conjunctival edema, and ciliary flush in bimicrosocpy examinations were significantly better for subjects treated with bromfenac, supporting the efficacy of bromfenac ophthalmic solution $0.09 \%$ in reducing inflammation after cataract surgery. CME was reported as an adverse event for $1.4 \%$ of the subjects in the bromfenac group, compared with $4.7 \%(\mathrm{p}<0.05)$ in the vehicle group, suggesting that bromfenac treatment may have reduced the incidence of this important potential complication of cataract surgery. ${ }^{44}$

Bromfenac ophthalmic solution $0.09 \%$ was effective for the rapid resolution of ocular pain after cataract surgery. There was a statistically significant difference between the bromfenac and placebo groups demonstrated in these phase III clinical trials. Median time to resolution of ocular pain was 2 days with bromfenac, vs 5 days with a placebo $(p<0.0001) .{ }^{44}$ There are 2 very important aspects of the design of these clinical trials which distinguish them from previous ophthalmic studies. ${ }^{44}$ First, no predosing of the agent or concomitant steroid use was permitted before randomization into the clinical study. Second, the degree of ocular inflammation at entry into the clinical trial was moderate to severe. In a separate clinical trial with ketorolac, statistical significance for ocular pain was not reached until visit days 14 to $16(\mathrm{p}=0.049) .{ }^{20}$

\section{Safety and tolerability of bromfenac ophthalmic solution}

Significant adverse effects have been associated with the use of systemic NSAIDs. ${ }^{45}$ Diclofenac induced hepatotoxicity has been well characterized ${ }^{46,47}$ and ketorolac has been associated with gastrointestinal, renal, and hematologic adverse reactions and 143 deaths by $1993 .{ }^{48}$ Subjects in clinical trials of long-term treatment with the oral bromfenac, ${ }^{28,29}$ were found to have an increased incidence of liver enzyme elevations. While there were no cases of serious liver injury, the FDA prescribing information for oral bromfenac was 
subsequently amended to include a re-emphasized "black box" warning limiting use to no more than 10 days. In a rabbit model of ocular inflammation, effects of bromfenac were observed in the contralateral eye, suggesting possible systemic effects. ${ }^{49}$

\section{Adverse effects of bromfenac}

The most common adverse events reported with bromfenac included abnormal sensation in the eye, conjunctival hyperemia, eye irritation (including burning/stinging), eye pain, eye pruritis, eye redness, headache, and iritis. These events were reported in $2 \%$ to $7 \%$ of patients (Table 4 ).

No deaths have been reported with bromfenac $0.09 \%$ ophthalmic solution. In postmarketing surveillance, less frequently reported events observed included corneal erosion, corneal perforation, corneal thinning, and epithelial breakdown. During the two phase III clinical trials described above, the ocular adverse events were mild, and occurred less frequently with bromfenac than with placebo. A component of postsurgery ocular inflammation is ocular irritation. The rapid onset of bromfenac in the treatment of postsurgical inflammation diminishes ocular irritation, including burning and stinging. ${ }^{50}$

Bromfenac ophthalmic solution is in Pregnancy Category C. Teratogenicity has not been observed in animal studies. However, bromfenac was associated with embryo-fetal lethality, increased neonatal mortality, and reduced postnatal growth at high doses in rats, and increased postimplantation losses at high doses in rabbits. Use during pregnancy is recommended only if the potential benefit justifies the potential risk to the fetus. Use should be avoided during late pregnancy because of the known effects of

Table 4 Common ocular adverse events of xibrom (bromfenac ophthalmic solution) $0.09 \%$ vs vehicle 7,31

\begin{tabular}{lll}
\hline Ocular adverse events & Bromfenac 0.09\% & Vehicle \\
\hline Number & $356(100 \%)$ & $171(100 \%)$ \\
Iritis & $7.0 \%$ & $18.1 \%$ \\
Abnormal sensation in eye & $6.5 \%$ & $8.2 \%$ \\
Eye pain & $4.2 \%$ & $11.7 \%$ \\
Eye pruritis & $3.9 \%$ & $2.9 \%$ \\
Posterior capsule opacification & $3.9 \%$ & $4.1 \%$ \\
Partial vision loss & $3.1 \%$ & $9.4 \%$ \\
Eye irritation (burning/stinging) & $2.5 \%$ & $4.7 \%$ \\
Eye redness & $2.2 \%$ & $7.6 \%$ \\
Conjunctival hyperemia & $2.2 \%$ & $11.1 \%$ \\
Photophobia & $2.0 \%$ & $11.1 \%$ \\
\hline
\end{tabular}

prostaglandin-inhibiting agents on the fetal cardiovascular system (closure of the ductus arteriosus). ${ }^{50}$

Senju Pharmaceuticals Co, Ltd, has developed bromfenac sodium hydrate ophthalmic solution $0.1 \%$ as a therapeutic for external or anterior ocular inflammatory diseases, such as blepharitis, conjunctivitis, scleritis, episcleritis, and postoperative ocular inflammation. ${ }^{34,41}$ Results from preclinical studies demonstrate that bromfenac ophthalmic solution is noncarcinogenic and nonteratogenic, does not accumulate in any organ, is cleared rapidly from all tissues, and does not affect reproductive performance. There are no known interactions of bromfenac with other drugs, whether ophthalmic or nonophthalmic, or with medical conditions. Results from clinical studies demonstrated no abnormal findings specific to dose concentrations or clinically significant changes in liver chemistries indicative of hepatotoxicity. Bronuck was approved by the Ministry of Health, Labour and Welfare of Japan in 2000 following the completion of phase III clinical trials, and to date, there have been over 10 million patient uses. ${ }^{45}$ For most patients, ophthalmic administration has been 1 drop daily for 14 days. Reports of serious and nonserious adverse effects have been low since drug approval and there have been no reports of liver toxicity according to the postmarketing safety surveillance data available.

\section{The relationship of corneal melts with bromfenac ophthalmic solution}

Arguably the most serious side effect that has occurred with topical NSAID use is corneal melting and ulceration, which were reported by Lin et $\mathrm{al}^{51}$ following use of diclofenac sodium. Subsequently, other cases of corneal melt following the use of diclofenac as well as ketorolac and nepafenac have been reported. ${ }^{52-58}$

Three case reports by Asai et $\mathrm{al}^{57}$ in Japan have been published describing corneal melting in patients using bromfenac ophthalmic solution. Each of the three cases of corneal stromal melting occurred in the setting of 3 common factors: pre-existing conditions that predisposed the cornea to toxicity, bromfenac use, and ofloxacin use. None of the patients in the report had undergone cataract extraction. One patient had been using bromfenac ophthalmic solution for 40 days. All cases were resolved with conservative treatment that included the use of a bandage soft contact lens and/or antibiotics and lubrication.

Isawi recently published a case report of bilateral corneal melting and perforation in Stevens Johnson syndrome (SJS) following topical bromfenac use for 2 weeks. The tear deficiency in this SJS patient may have predisposed her to 
NSAID-induced epithelial cell healing disturbances, which may have led to the corneal melting and perforation. ${ }^{58}$

It is important to note that in the three cases reported by Asai, ${ }^{57} 2$ of the patients had severe ocular surface compromise: a 58-year-old with Fuchs' dystrophy-induced bullous keratopathy and a patient being treated for a bacterial corneal ulcer in 1 eye. Given that previous studies have implicated NSAIDs in decreasing corneal epithelium migration ${ }^{59}$ and in delaying wound healing, ${ }^{60}$ it may be that with underlying surface abnormalities, the capacity of the corneal epithelium to self-repair may be diminished and thus a smaller insult may precipitate a more severe reaction, such as corneal melting. These cases highlight the importance of being selective when prescribing topical NSAIDs, especially in patients with underlying ocular surface abnormalities.

\section{Systemic safety of bromfenac ophthalmic solution}

Stewart et $\mathrm{al}^{45}$ evaluated the systemic safety of bromfenac ophthalmic solution $0.09 \%$ vs placebo for the treatment of postoperative inflammation and reduction of ocular pain in subjects who have undergone cataract extraction. The study was 2 phase III, multicenter, randomized, double-masked, parallel, placebo-controlled clinical trials with data pooled for analysis as described above. This study showed that bromfenac ophthalmic solution $0.09 \%$ dosed twice a day for 14 days after cataract surgery demonstrated neither treatmentrelated systemic adverse events (SAEs) nor evidence of hepatic toxicity. No treatment-related serious SAEs occurred in either clinical trial, and there was a low occurrence of systemic effects overall. The systemic results with bromfenac ophthalmic solution reported in this paper support the postmarket clinical experience in Japan where there were no reports of systemic drug-related adverse events. ${ }^{61}$

In contrast, systemic adverse reactions have been reported for earlier generations of ophthalmic NSAIDs. Diclofenac sodium ophthalmic solution $0.1 \%$, which is currently approved by the FDA for postoperative inflammation following cataract extraction, was associated with abdominal pain, asthenia, chills, dizziness, facial edema, fever, headache, insomnia, nausea, pain, rhinitis, viral infection, and vomiting ${ }^{46} \mathrm{Clinical}$ trials of ophthalmic nepafenac $\left(\mathrm{Nevanac}^{\circledR}\right)$ were associated with headache, hypertension, nausea/vomiting, and sinusitis in $1 \%$ to $4 \%$ of subjects from clinical studies. Dosing with the topical solution of either diclofenac or ketorolac is 4 times a day and nepafenac is dosed 3 times a day. Bromfenac ophthalmic solution $0.09 \%$ is the only bid ophthalmic NSAID approved in the United States. The decreased dosage may further limit drug and preservative exposure and minimize systemic absorption. ${ }^{45}$

\section{Tolerability and convenience of bromfenac}

The twice-daily dosing schedule is convenient for the postcataract surgery patient population and may enhance patient compliance and adherence to the recommended dosage schedule. Multiple clinical studies have shown that patient compliance in administering medications, especially in older subjects, improve with less frequent dosing. ${ }^{62,63}$ No other ophthalmic NSAID has been approved by the FDA with a twice-daily dosing regimen. In contrast to the thrice-daily or 4 times daily dosing schedules of other ophthalmic NSAIDs, the twice-daily dosing schedule reduces drug exposure while still maintaining significant clinical efficacy.

There are additional convenience factors for bromfenac in comparison to other NSAIDs: ${ }^{44}$ bromfenac ophthalmic solution does not require shaking before administration, whereas nepafenac, a suspension, requires shaking before each administration; less frequent dosing also means reduced exposure to the preservative benzalkonium chloride. The level of benzalkonium chloride in bromfenac ophthalmic solution $0.09 \%$ is $0.005 \%$, the same as in nepafenac ophthalmic solution $0.1 \%$. In contrast, the percentage of benzalkonium chloride is higher in ketorolac tromethamine ophthalmic solution $0.4 \%(0.006 \%)$ and even higher in ketorolac tromethamine ophthalmic solution $0.5 \%$ (0.01\%). Higher levels of benzalkonium chloride have been associated with corneal epithelial dysfunction. ${ }^{64}$

\section{Other clinical applications of bromfenac}

\section{Increasing use of new generation NSAIDs in the treatment of CME Brief overview of CME}

Since its first recognition and description in 1974, ${ }^{65} \mathrm{CME}$ has been recognized as the most common cause of decreased vision postoperatively in uneventful cataract surgery ${ }^{66} \mathrm{CME}$ is caused by cystic accumulation of intraretinal fluid in the outer plexiform and inner nuclear layers of the retina, as a result of the breakdown of the blood-retinal barrier. ${ }^{67} \mathrm{CME}$ can be a serious consequence of numerous ocular procedures and conditions, including cataract surgery, ocular inflammatory disease, retinal vascular diseases, and tractional disorders. ${ }^{68}$ It is not a disease itself, rather the endpoint of a variety of processes that lead to the accumulation of fluid in 
the central retina. ${ }^{69}$ It can present with symptoms of blurred or declined central vision, and painless retinal inflammation or swelling. Vision loss is usually temporary, with rare incidences of permanent visual loss. ${ }^{20}$ Often, however, the condition is often asymptomatic and may be detected only with fluorescein angiography or optical coherence tomography. ${ }^{70}$ Studies suggest that the rate of clinical CME is in the range of $1 \%$ to $2 \%,{ }^{71}$ whereas the incidence of angiographic CME may be as high as $9 \%$ to $19 \% .^{72,73}$

Since inflammation is a known risk factor for the development of $\mathrm{CME},{ }^{74}$ anti-inflammatory corticosteroids are commonly used to treat this condition, although they are associated with serious side effects, including elevated IOP and posterior subcapsular cataract. ${ }^{75}$ Because of this, less toxic but equally effective alternatives to corticosteroids are desirable.

Although none of the ophthalmic NSAIDs currently available in the United States are indicated for the preventitive treatment of CME after cataract surgery, topical NSAIDs have increasingly been used over the past 2 decades. NSAIDs, specifically indomethacin, first demonstrated efficacy for the prevention of pseudophakic CME in $1977,{ }^{76}$ but it was not until much later that ketorolac $0.5 \%$ and diclofenac $0.1 \%$ proved effective in treating this condition. ${ }^{77,78}$

\section{Prednisolone vs prednisolone/nepafenac and the rate of pseudophakic CME}

While no randomized trials have yet been conducted to test the ability of the two new-generation topical NSAIDs, nepafenac and bromfenac, numerous reports suggest that these agents also have activity against this condition. ${ }^{79} \mathrm{~A}$ study by Wolf et $\mathrm{al}^{25}$ compared the incidence of visually significant pseudophakic macular edema after uneventful phacoemulsification in patients treated postoperatively with topical prednisolone and those treated with topical prednisolone and nepafenac $0.1 \%$ suspension and found that those treated with topical prednisolone alone had a significantly higher incidence of visually significant pseudophakic macular edema than those treated with topical prednisolone and nepafenac.

\section{Bromfenac vs ketorolac vs diclofenac}

for the treatment of acute pseudophakic CME

Rho et a ${ }^{80}$ presented results of a study comparing bromfenac ophthalmic solution with diclofenac and ketorolac for the treatment of acute pseudophaakic CME. Sixty-four eyes with documented CME after uncomplicated cataract surgery were randomized to receive bromfenac bid, diclofenac qid, or ketorolac qid for 3 months. After the treatment period, all 3 treatment groups achieved statistically significant visual improvement, evaluated by Early Treatment Diabetic Retinopathy study letter gained over baseline, and, although the differences between the groups were not significant, there was a trend toward significance for the bromfenac group. Rho concluded that twice-daily bromfenac was statistically as effective as diclofenac or ketorolac dosed 4 times daily. ${ }^{80}$

\section{Bromfenac for the prevention of miosis during cataract surgery}

Some studies suggest that bromfenac ophthalmic solution is clinically beneficial in a variety of other therapeutic and surgical settings that fall outside of the current United States-approved indication for bromfenac in the treatment of ocular inflammation and reduction of ocular pain after cataract extraction. ${ }^{7}$ The first use of NSAIDs in ophthalmology was for the prevention of miosis during cataract surgery. ${ }^{24}$ Ohara and colleagues ${ }^{81}$ compared bromfenac ophthalmic solution with diclofenac ophthalmic solution in an open label study of this application. After drop instillation at 60 and 30 minutes before surgery, pupil diameter and miosis rates were evaluated. The investigators concluded that bromfenac exerted a comparable antimiotic effect to diclofenac and would therefore be useful in suppressing miosis during cataract surgery. ${ }^{81}$

\section{Bromfenac for the treatment of allergic conjunctivitis}

NSAIDs have been found to be effective for the treatment of seasonal allergic conjunctivitis. Bromfenac ophthalmic solution was compared with the ophthalmic mast cell stabilizer pemirolast potassium for the treatment of seasonal allergic conjunctivitis in a clinical study by Miyake Kashima et al. ${ }^{82}$ After bid dosing of each type of drop in the opposite eye for 1 week, subjects were evaluated for improvement in 5 ocular signs and subjective symptoms. Both drugs improved 4 of 5 objective signs but there was no significant difference between the drugs in objective efficacy. Neither drug significantly improved subjective symptoms after this brief treatment period nor was there any difference between them in the subjects' assessment. ${ }^{82}$

\section{Bromfenac for the treatment of anterior uveitis}

Usui and Masude ${ }^{83}$ reported on the evaluation of twice-daily bromfenac ophthalmic solution for the treatment of anterior uveitis over both 2-week and 12-week treatment courses. 
The investigators concluded that bromfenac seemed to reduce inflammation associated with anterior uveitis with minimal side effects, potentially providing a safer alternative to longterm treatment with ophthalmic steroids.

\section{Conclusion}

In multiple comparative trials, bromfenac ophthalmic solution $0.09 \%$ has been shown to provide safe and effective relief of perioperative inflammation and pain following cataract surgery. The unique chemical structure of bromfenac makes it both a potent inhibitor of COX-2 enzyme and a highly lipophilic molecule that rapidly penetrates to produce early and sustained drug levels in all ocular tissues. Clinically, these pharmacokinetic features are manifested in a rapid reduction of postsurgical inflammation and pain with bid dosing. ${ }^{7}$ Bromfenac also has an extensive safety record with over 10 million ophthalmic uses globally. Further clinical investigations will explore the expanding use of bromfenac in a variety of other clinical settings, including, but not limited to, the management of ocular inflammation and pain following cataract surgery.

\section{Disclosures}

The authors have no conflicts of interest to declare.

\section{References}

1. Ahuja M, Dhake AS, Sharma SK, Majumdar DK. Topical Ocular Delivery of NSAIDs. AAPS J. 2008 Apr 25.

2. McColgin AZ, Heier JS. Control of intraocular inflammation associated with cataract surgery. Curr Opin Ophthalmol. 2000;11:3-6.

3. Perry HD, Donnenfeld ED. An update on the use of ophthalmic ketorolac tromethamine 0.4\%. Expert Opin Pharmacother. 2006;7(1):99-107.

4. Chang JH, Chung H. Non-steroidal anti-inflammatory drug and endotoxin induced unveitis. Korean J Ophthalmol. 1993;7:35-42.

5. Polansky JR, Weinreb RN. Steroids as anti-inflammatory agents. In: Pharmacology of the Eye. Sears ML, editor. Springer-Verlag, New York; 1984. p. 460-538.

6. Campbell WB, Halushka PV. Lipid-derived autacoids: eicosanoids and platelet-activating factor: In: Hardman JG, Limbird LE, Molinoff PB, et al. editors. Goodman and Gilman's The Pharmacological Basis of Therapeutics. 9th ed. New York, NY: McGraw-NetHill; 1996. p. 601-616.

7. Donnenfeld ED, Donnenfeld A. Global experience with Xibrom (bromfenac ophthalmic solution) $0.09 \%$ : the first twice-daily ophthalmic nonsteroidal anti-inflammatory drug. Int Ophthalmol Clin. 2006;46(4):21-40.

8. Oka T, Shearer TR, Azuma M. Involvement of cyclooxygenase-2 in rat models of conjunctivitis. Curr Eye Res. 2004;29:27-34.

9. McGhee CN, Dean S, Danesh-Meyer H: Locally administered ocular corticosteroids: benefits and risks. Drug Saf. 2002;25:33-55.

10. Samiy N, Foster CS. The role of non-steroidal anti-inflammatory drugs in ocular inflammation. Int Ophthalmol Clin. 1996;36:195-206.

11. Flach AJ. Topical nonsteroidal anti-inflammatory drugs in ophthalmology. Int Ophtalmol Clin. 2002;42:1-11.

12. Rojanasakul Y, Robinson JR. Transport mechanisms of the cornea: characterization of barrier permselectivity. Int J Pharm. 1989;55:237-246.

13. Schalnus R. Topical nonsteroidal anti-inflammatory therapy in ophthalmology. Ophthalmologica. 2003;217:89-98.
14. Gupta M, Majumdar DK. Effect of concentration, $\mathrm{pH}$ and preservatives on in vitro transcorneal permeation of ibuprofen and flurbiprofen from non-buffered aqueous drops. Indian J Exp Biol. 1997;35:844-849.

15. Ahuja M, Dhake AS, Majumdar DK. Effect of formulation factors on in vitro permeation of diclofenac from experimental and marketed aqueous eye drops through excised goat cornea. Yakugaku Zasshi. 2006;126:1369-1375.

16. Voltaren Ophthalma ${ }^{\circledR}$ (diclofenac) [package insert]. Duluth, GA: Novartis Ophthalmics; 2003.

17. Acular $^{\circledR}$ (ketorolac) [package insert]. Irvine, CA: Allergan Inc; 2002.

18. Nevanac ${ }^{\circledR}$ (nepafenac) [package insert]. Fort Worth: Alcon Laboratories; 2005.

19. Xibrom $^{\circledR}$ (bromfenac) [package insert]. Irvine, CA: ISTA Pharmaceuticals, Inc; 2006.

20. O'Brien TP. Emerging guidelines for the use of NSAID therapy to optimize cataract surgery and patient care. Curr Med Res Opin. 2005;21:1131-1137.

21. Heier JS, Topping TM, Baumann W, et al. Ketorolac versus prednisolone versus combination therapy in the treatment of acute pseudophakic cystoid macular edema. Ophthalmology. 2000;107:2034-2039.

22. Roberts CW, Brennan KM. A comparison of topical dicolfenac with prednisolone for postcataract inflammation. Arch Ophthal. 1995;113:725-727.

23. El-Harazi SM, Ruiz RS, Feldman RM, et al. A randomized double-masked trial comparing ketorolac tromethamine $0.5 \%$, diclofenac sodium $0.1 \%$, and prednisolone acetate $1 \%$ in reducing post-phacoemulsification flare and cells. Ophthalmic Surg Lasers. 1998;29:539-544.

24. Flach AJ. Nonsteroidal anti-inflammatory drugs. In: Tasman W, editor. Duane's foundations of clinical ophthalmology. Philadelphia (PA): Lippincott; 1994. p. 1-32.

25. Wolf EJ, Braunstein A, Shih C, Braunstein RE. Incidence of visually significant pseudophakic macular edema after uneventful phacoemulsification in patients treated with nepafenac. J Cataract Refract Surg. 2007 Sep; 33(9):1546-1549.

26. Hsu JK, Johnston WT, Read RW, et al. Histopathology of corneal melting associated with diclofenac use after refractive surgery. $J$ Cataract Refract Surg. 2003;29:250-256.

27. Ke T-L, Graff G, Spellman JM, Yanni JM. Nepafenac a unique nonsteroidal prodrug with potential utility in the treatment of trauma-induced ocular inflammation: II. In vitro bioactivation and permeation of external ocular barriers. Inflammation. 2000;24:371-384.

28. Brown HB, Taylor P. Muscarinic receptor agonists and antagonists. In: Hardman JG, Limbird LE, Molinoff PB, Ruddon RW, editors. Goodman and Gilman's The Pharmacological Basis of Therapeutics. 9th ed. New York: McGraw-Hill; 1996. p. 141-160.

29. Sancilio LF, Nolan JC, Wagner LE, Ward JW. The analgesic and antiinflammatory activity and pharmacologic properties of bromfenac. Arzneimittelforschung. 1987;37:513-519.

30. Walsh DA, Moran HW, Shamblee DA, et al. Antiinflammatory agents. 3. Synthesis and pharmacological evaluation of 2-amino-3-benzoylpheylacetic acid and analogues. J Med Chem. 1984;27:1379-1388.

31. Data on file. ISTA Pharmaceuticals, Inc.

32. Waterbury LD, Silliman D, Jolas T. Comparison of cyclooxygenase inhibitory activity and ocular anti-inflammatory effects of ketorolac tromethamine and bromfenac sodium. Curr Med Res Opin. 2006;22:1133-1140.

33. Yanni JM, Graff G, Hellberg MR. Topically administrable compositions containing 3-benzoylphenylaceteic acid derivatives for treatment of ophthalmic inflammatory disorders. Alcon Laboratories, Inc., assignee. US Patent 5,475,034. December 12, 1995.

34. Ogawa T, Miyake K, McNamara TR, et al. Pharmacokinetic profile of topically applied bromfenac sodium ophthalmic sodium ophthalmic solution $0.1 \%$ in subjects undergoing cataract surgery. Proceedings of the Association for Research in Vision and Ophthalmology (ARVO) Annual Meeting, Ft. Lauderdale, FL, April 30-May 4, 2006. A687. 
35. Bakalyan GA, Deshmukh HM, Patterson H, et al. Concentrations of radioactivity in ocular tissues after a single topical dose of C-bromfenac ophthalmic solution. Proceedings of the American Society of Cataract and Refractive Surgery (ASCRS) Meeting, San Francisco, CA, March 17-22, 2006. Abstract p. 227.

36. Helberg MR, Nixon JC. Use of non-steroidal anti-inflammatory agents in combination with compounds that have PF prostaglandin agonist activity to treat glaucoma and ocular hypertension. Alcon Laboratories, Inc., assignee. US Patent 6,342,524 B1. January 29, 2002.

37. McNamara TR, Baklayan GA, Deshmukh HM, et al. Concentrations of radioactivity in ocular tissues after a single $0.09 \%$ topical dose of C-bromfenac ophthalmic solution. Proceedings of the Association for Research in Vision and Ophthalmology (ARVO) Annual Meeting, Ft. Lauderdale, FL, April 30-May 4, 2006. A687.

38. Masuda K, Fukado Y, Shimizu H, et al. Effect of bromfenac sodium ophthalmic solution on inflammation following intraocular lens implantation. Ganka Rinsho Iho (Jpn Rec Vin Ophthalmol). 1997;91:745-750.

39. Walters T, Raizman M, Ernest P, Gayton J, Lehmann R. In vivo pharmacokinetics and in vitro pharmacodynamics of nepafenac, amfenac, ketorolac, and bromfenac. J Cataract Refract Surg. 2007;33(9): 1539-1545.

40. Bucci F, Waterbury D. Comparison of ketorolac $0.4 \%$ and bromfenac $0.09 \%$ at trough dosing: Aqueous drug absorption and prostaglandin E2 levels. J Cataract Refract Surg. 2008;34:1509-1512.

41. Kawaguchi T, Kida T, Nemoto S, et al. Effect of bromfenac ophthalmic solution on ocular inflammation and corneal epithelial barrier function following cataract surgery. Folia Ophthalmol Jpn. 2003;54:276-279.

42. Takamatsu F, Shiroyama N, Saito Y, et al. Efficacy and adverse effects of bromfenac ophthalmic solution following cataract surgery. Rinsho Ganka (Jpn J Clin Ophthalmol). 2003;57:1233-1237.

43. Ohara K, Ohkuba A, Miyamoto T, et al. Effect of bromfenac sodium on postoperative inflammation. Jpn J Catarac Refract Surg. 2004;18:1-12.

44. Donnenfeld ED, Holland EJ, Stewart RH, Gow JA, Grillone LR Bromfenac Ophthalmic Solution 0.09\% (Xibrom) Study Group. Bromfenac ophthalmic solution $0.09 \%$ (Xibrom) for postoperative ocular pain and inflammation. Ophthalmology. 2007;114(9):1653-1662.

45. Stewart RH, Grillone LR, Shiffman ML, Donnenfeld ED, Gow JA; Bromfenac Ophthalmic Solution 0.09\% Study Group. The systemic safety of bromfenac ophthalmic solution $0.09 \%$. J Ocul Pharmacol Ther. 2007;23(6):601-612.

46. Greaves RR, Agarwal A, Patch D, et al. Inadvertent diclofenac rechallenge from generic and non-generic prescribing, leading to liver transplantation for fulminant liver failure. Eur J Gastroenterol Hepatol. 2001;13:71-73.

47. Aithal GP. Diclofenac-induced liver injury: A paradigm of idiosyncratic drug toxicity. Exp Opin Drug Saf. 2004;3:519-523.

48. Macario A, Lipman AG. Ketorolac in the era of cyclo-oxygenase-2 selective nonsteroidal anti-inflammatory drugs: A systematic review of efficacy, side effects, and regulatory issues. Pain Med. 2001;2:336-351.

49. Waterbury LD. Marked contralateral activity of bromfenac in a rabbit model of ocular inflammation. Invest Ophthalmol Vis Sci. 2005;46: Abstract 3936.

50. National PBM Drug Monograph, Bromfenac 0.09\% Ophthalmic Solution $\left(\mathrm{Xibrom}^{\circledR}\right)$ June 2006. Available from: http://www.pbm. va.gov/monograph/Bromfenac0.09PercentOphthalmicSolution.pdf.

51. Lin JC, Rapuano CJ, Laibson PR, et al. Corneal melting associated with use of topical nonsteroidal anti-inflammatory drugs after ocular surgery. Arch Ophthalmol. 2000;118:1129-1132.

52. Congdon NG, Schein OD, von Kulajta P, et al. Corneal complications associated with topical ophthalmic use of nonsteroidal anti-inflammatory drugs. J Cataract Refract Surg. 2001;27:622-631.

53. Flach AJ. Corneal melts associated with topically applied nonsteroidal anti-inflammatory drugs. Trans Am Ophthamol Soc. 2001; 99:205-212.

54. Guidera AC, Luchs JI, Udell IJ. Keratitis, ulceration, and perforation associated with topical nonsteroidal anti-inflammatory drugs. Ophthalmology. 2001;108:936-944.
55. Mian SI, Gupta A, Pineda R II. Corneal ulceration and perforation with ketorolac tromethamine (Acular) use after PRK. Cornea. 2006; 25:232-234.

56. Wolf EJ, Kleiman LZ, Schrier A. Nepafenac-associated corneal melt. $J$ Cataract Refract Surg. 2007;33(11):1974-1975.

57. Asai T, Nakagami T, Mochizuki M, et al. Three cases of corneal melting after instillation of a new nonsteroidal anti-inflammatory drug. Cornea. 2006:25:224-227.

58. Isawi H, Dhaliwal DK. Corneal melting and perforation in Stevens Johnson syndrome following topical bromfenac use. J Cataract Refract Surg. 2007;33(9):1644-1646.

59. Hashizume N, Saika S, Okada Y, et al. Effects of anti-inflammatory drugs on migration of the rabbit corneal epithelium. J Cataract Rrefract Surg. 2001;27:1499-1502.

60. Hersh PS, Rice BA, Baer JC, et al. Topical nonsteroidal agents and corneal would healing. Arch Ophthalmol. 1990;108:577-583.

61. Kitao, N, Shimoji, H, Fukuda M. Postmarketing surveillance of bromfenac sodium (Bronuck) ophthalmic solution. Jn Eye. 2005;22:1299-1308.

62. Taylor SA, Galbraith SM, Mills RP. Causes of non-compliance with drug regimens in glaucoma patients: a qualitative study. $J$ Ocul Pharmacol Ther. 2002;18:401-409.

63. Patel SC, Spaeth GL. Compliance in subjects prescribed eye drops for glaucoma. Ophthalmic Surg. 1995;26:233-236.

64. Cha SH, Lee JS, Oum BS, Kim CD. Corneal epithelial cellular dysfunction from benzalkonium chloride (BAC) in vitro. Clin Experiment Ophthalmol. 2004;32:180-184.

65. Flach AJ. Cyclo-oxygenase inhibitors in ophthalmology. Surv Ophthalmol. 1992 Jan-Feb; 36(4):259-284.

66. Flach AJ. The incidence, pathogenesis, and treatment of cystoids macular edema following cataract surgery. Trans Am Ophthalmol Soc. 1998;96:557-634.

67. Quinn CJ: Cystoid macular edema. Optom Clin. 1996;5(1):111-130.

68. Tranos PG, Wickremasinghe SS, Stangos NT, Topouzis F, Tsinopoulos I, Pavesio CE. Macular edema. Survev Ophthalmol. 2004;49:470-490.

69. Colin J. The role of NSAIDs in the management of postoperative ophthalmic inflammation. Drugs. 2007;67(9):1291-1308.

70. Roberts CW: Pretreatment with topical diclofenac sodium to decrease postoperative inflammation. Ophthalmology. 1996;103:636-639.

71. Ray S, D’Amico DJ. Pseudophakic macular edema. Semin Ophthalmol. 2002;17:167-180.

72. Ursell PG, Spalton DJ, Whitcup SM, Nussenblatt RB. Cystoid macular edema after phacoemulsification: relationship to bloodaqueous barrier damage and visual acuity. $J$ Cataract Refract Surg. 1999;25(11):1492-1497.

73. Mentes J, Erakgun T, Afrashi F, Kerci G. Incidence of cystoids macular edema after uncomplicated phacoemulsification. Ophthalmologica. $2003 ; 217(6): 408-412$.

74. Gulkilik G, Kocabora S, Taskapili M, Engin G. Cystoid macular edema after phacoemulsification: risk factors and effect on visual acuity. Can J Ophthalmol. 2006;4:699-703.

75. Sivaprasad S, McCluskey P, Lightman S. Intravitreal steroids in the management of macular oedema. Acta Ophthalmol Scand. 2006;84:722-733.

76. Miyake K. Prevention of cystoid macular edema after lens extraction by topical indomethacin (I). A preliminary report. Graefes Arch Klin Exp Ophthalmol. 1977;203:81-88.

77. Flach AJ, Dolan BJ, Irvine AR. Effectiveness of ketorolac tromethamine $0.5 \%$ ophthalmic solution for chronic aphakic and pseudophakic cystoid macular edema. Am J Ophthalmol. 1987;103:479-486.

78. McColgin AZ, Raizman MB. Efficacy of topical Voltaren in reducing the incidence of postoperative cystoid macular edema. Invest Ophthalmol Vis Sci. 1999;40(Suppl):289.

79. Gross JG. Xibrom (bromfenac) reduces cystoid macular edema associated with vein occlusions, macular epiretinal membrane, diabetic retinopathy and age related macular degeneration. Poster F-3 presented at: Annual Meeting of the Retina Society. September 27-30; Boston. 
80. Rho DS, Soll SM, Markovitz BJ. Bromfenac $0.09 \%$ versus diclofenac sodium $0.1 \%$ verseus ketorolac tromethamine $0.5 \%$ in the treatment of acute pseudophakic cystoids macular edema: diclofenac versus ketorolac. Proceedings of the Association for Research in Vision and Ophthalmology (ARVO) Annual Meeting, Ft. Lauderdale, FL, April 30-May 4, 2006. AF211.

81. Ohara K, Ohkubo A, Miyamoto T, et al. Prevention of miosis during cataract surgery by topical bromfenac sodium. Rinsho Ganka (Jpn J Clin Ophthalmol). 2004;58:1325-1328.
82. Miyake-Kashima M, Takano Y, Tanaka M, et al. Comparision of $0.1 \%$ bromfenac sodium and $0.1 \%$ pemirolast potassium for the treatment of allergic conjunctivitis. Jpn J Ophthalmol. 2004;48:587-590.

83. Usui M, Masuda K. Effect of bromfenac sodium (AHR-10282B) eye drops on anterior uveitis. Ganka Rinsho Iho ( $\mathrm{R}$ Rev Clin Ophthalmol). 1997;91:39-44.

84. FitzGerald GA, Patrono C. The coxibs, selective inhibitors of cyclooxygenase-2. N Engl J Med. 2001;345(6):433-442. 